\title{
No sólo avasallada. Críticas y justificaciones sobre la justicia penal en la prensa argentina.
}

\section{Not only subjugated. Critiques and justifications about criminal justice in Argentina's Press}

Recibido el 3 noviembre 2015/Publicado el 28 noviembre 2016

\author{
Ezequiel Kostenwein \\ CONICET, UNLP, ICJ, Argentina
}

\begin{abstract}
RESUMEN
Este artículo presenta, en primer lugar, las percepciones que ofrecen los actores judiciales sobre el papel que juegan los medios de comunicación en general, y la prensa en particular, en la administración de justicia penal Argentina. Luego, analizar las representaciones y caracterizaciones que muestra $-\mathrm{y}$ hace circular- la prensa escrita sobre dicha justicia penal. En síntesis, rastrear un primer movimiento que es el que efectúa la prensa para introducirse en la justicia penal, y un segundo que es el que realiza la justicia penal para ser retratada por la prensa.
\end{abstract}

Palabras clave: Justicia penal, prensa, crítica

\begin{abstract}
This article shows, firstly, the perceptions offered by judicial actors on the role of the media in general and the press in particular in the Argentina's administration of criminal justice. Then we analyze the representations and characterizations of the criminal justice offered by the written press. In short, we track a first movement made by the press to enter the criminal justice system, and a second one concerning how the criminal justice try to be portrayed by the press.
\end{abstract}

Keywords: Criminal justice, press, critisism 


\section{Introducción}

Este artículo analizará las relaciones que se despliegan entre justicia penal y prensa escrita, relaciones que han sido exploradas escasamente en el ámbito argentino, en el sentido que no se conocen trabajos realizados al respecto. Por lo dicho, es importante comenzar a desarrollar indagaciones que busquen esclarecer esta problemática dado que se suelen proponer explicaciones bien sin sustento empírico, bien sin sustento teórico. En primer lugar, se distinguirán las percepciones que ofrecen los actores judiciales sobre el papel que poseen los medios de comunicación en general, y la prensa en particular. En segundo lugar, se considerarán las representaciones y caracterizaciones que ofrece $-\mathrm{y}$ hace circular- la prensa escrita sobre la administración de la justicia penal, las cuales abrevan de diferentes presupuestos y significados sobre lo que la mencionada justicia debería ofrecer, gestionar o remediar. Resumiendo, abordaremos un primer movimiento que efectúa la prensa hacia dentro de la justicia penal, y un segundo que realiza la justicia penal para ser retratada por la prensa.

\section{Método}

Para recuperar las percepciones de los actores judiciales sobre la prensa en Argentina, la técnica que empleamos para explorar el plano discursivo fue la entrevista semiestructurada (Kunz y Cardinaux, 2004; Marradi, Archenti y Piovani, 2007; Sautu, 2003) o antropológica (Guber, 2005). Partimos de una guía de preguntas y temas que nos facilitó dialogar sin tener que apegarnos a ningún orden inflexible preestablecido, permitiéndonos incorporar elementos no previstos que surgieron de conformidad a los vaivenes del diálogo con nuestros entrevistados. Fueron realizadas 46 entrevistas entre 2012 y 2015 a diferentes actores judiciales -en particular Defensores, Fiscales y Jueces de Garantías (JG)-, todas ellas gestionadas previamente por informantes clave y realizadas personalmente. Se efectuaron en el lugar de trabajo, excepto la de un Defensor y la de un experto en seguridad, que fueron llevadas a cabo en sus respectivas casas.

Como regla general, los actores judiciales mostraron una actitud reticente frente a la posibilidad de ser consultados, de hecho algunas entrevistas fueron canceladas de facto luego de la postergación de las mismas en varias oportunidades. Los Fiscales y JG 
han sido quienes durante el desarrollo de las entrevistas mantuvieron la mayor distancia mediante el uso de una formalidad en algunos casos excesiva. El caso de los Defensores fue distinto puesto que con el correr de las preguntas asumieron una actitud más llana cuya característica más frecuente fue la crítica hacia el funcionamiento de la justicia penal, a su selectividad, incluso a su indolencia en algunos casos.

Respecto de la prensa escrita, utilizamos como corpus los diarios Infobae, La Nación, Clarín y Página 12, cuyas notas fueron tomadas aleatoriamente una por mes desde enero de 2007 hasta mayo de 2015 considerando la más importante mensualmente en función de nuestros objetivos.

Elegimos los cuatro periódicos mencionados por dos motivos: primero, son los de mayor venta del país, y segundo, representan en líneas generales los enfoques ideológicos más relevantes en la discusión sobre el tema de la justicia penal. Se trata de periódicos tradicionales y reconocidos, con periodistas especializados en materia judicial, no necesariamente en justicia penal.

El lapso de tiempo escogido, entre 2007 y 2015, se decidió porque resultaba lo suficientemente amplio para evitar tomar noticias coyunturales sobre la justicia penal como si fueran frecuentes o sistemáticas. En este sentido, 8 años nos parecieron suficientes como para entender las imágenes de la justicia penal dentro de la prensa en perspectiva.

\section{Resultados}

\subsection{Observaciones desde la justicia penal}

Según hemos identificado para el caso argentino, la prensa consigue provocar y captar interés respecto a la justicia penal mediante un doble movimiento: uno, que partiendo de la misma prensa llega hasta la justicia penal, y el otro, que se dirige desde esta justicia penal hacia dicha prensa (Latour, 1983). Más concretamente, se trata de analizar cómo perciben los actores judiciales la incidencia de la prensa hacia dentro del ámbito en el que estos últimos trabajan, y luego, de qué es lo que refleja la mencionada prensa acerca del desempeño de la justicia penal.

Una de las formas privilegiadas para rastrear el primer movimiento, aquel que se encamina desde la prensa hacia la justicia penal, es a partir de las definiciones que 
ofrecen los operadores que trabajan allí acerca del tema. En el marco de trabajos previos (Kostenwein, 2015a, 2015b, 2105c), realizamos un total de 46 entrevistas a diferentes actores judiciales -en particular Defensores, Fiscales y Jueces de Garantías. Se trata de actores judiciales pertenecientes a la justicia penal de la Provincia de Buenos Aires. Las entrevistas fueron gestionadas previamente por informantes clave y realizadas personalmente. Todas ellas se efectuaron en el lugar de trabajo, excepto a un Defensor y un experto en seguridad, llevadas a cabo en sus respectivas casas. En las mismas consultamos a los operadores jurídicos por el papel que según ellos tiene la prensa -y los medios de comunicación en general- en la administración de justicia penal.

A partir de estas conversaciones pudimos observar, en primer lugar, que no existe unanimidad entre los actores judiciales en el momento de sugerir la influencia que la prensa tendría dentro de la mencionada justicia. Como segunda cuestión, y sirviéndonos de los testimonios de estos actores, logramos elaborar tres modelos generales o "gramáticas argumentativas" (Chateauraynaud, 2005) en los que podrían agruparse sus distintas justificaciones, por medio de los cuales entender con mayor precisión el movimiento "de ingreso" que realiza la prensa hacia dentro de la justicia penal.

\section{Prensa hegemónica, voluntarismo judicial y astucia}

Uno de los modelos al respecto, que podríamos definir como el de la "prensa hegemónica", es el que considera muy influyentes a los medios de comunicación en general, sin la necesidad de ofrecer acerca de estos últimos matices o especificaciones. La prensa es presentada como un factor determinante para entender el funcionamiento de la justicia penal, en el sentido de fijar límites y ejercer presiones (Williams, 2009). A raíz de que la incidencia de los medios de comunicación es reconocida explícitamente, se vuelve arriesgado considerar que el investigador deba desentrañar el papel que juegan dichos medios de comunicación como elemento que el sentido común judicial calla u oculta. Un ejemplo es el siguiente testimonio:

Mi percepción es que su influencia es absoluta. No tengo modo de probarlo, pero creo que sí. Por ejemplo, el caso de la Hiena Barrios, se seguía de acuerdo a lo que se decía afuera, tenías una Fiscal que le pidió una detención, y la Jueza de Garantías se la concedió. La Cámara [de Apelación y Garantías de la Provincia de Buenos Aires] la mató [le revocó la decisión] a la Jueza de Garantías que pensó que eso era lo correcto. La Cámara le pega [le revoca la decisión] porque dice que no se puede pedir prisión 
preventiva para un delito culposo que nunca habías dictado. Entonces, la Jueza de Garantías hizo la lectura del afuera, y la Cámara otra. Y la Fiscal lo hace por dolo eventual sabiendo que no lo es, pero lo hace para mostrarse más cerca de las víctimas. Y la Fiscal armó una causa y va a perder el juicio (Defensor Oficial, Departamento Judicial de Mar del Plata).

Por lo tanto, en este modelo los medios de comunicación -entre ellos la prensaaparecen informando de manera inexacta las cuestiones técnico-jurídicas, y en segundo lugar, "forzando" a los actores judiciales a echar mano de medidas más punitivas debido principalmente al temor que estos mismos actores tienen de ser denostados por los mencionados medios.

En otro de los modelos, ligado a cierto "voluntarismo judicial", tanto los medios de comunicación como la prensa son considerados factores que deben tenerse en cuenta, pero a los que es posible contrarrestar - o neutralizar, incluso- si el operador jurídico enfrenta las "embestidas" de la prensa. Aquí, los testimonios no definen a esta última como portadora de una influencia inquebrantable, sino a los actores judiciales como competentes y en condiciones de ponerle límites.

Y, depende de la personalidad del Juez de Garantías o del Fiscal, no debería influenciarte para que hagas las cosas de manera distinta a la que pensás. Yo tuve presiones: la no detención de X acusado por la Fiscalía del triple crimen X. El día de las elecciones nacionales había un pedido expreso del Gobernador y del Ministro de Seguridad X que era el imputado el que había cometido el crimen. Me amenazaron con un juicio político, y yo no le di la detención porque no estaban los elementos necesarios en aquel momento. Y sabemos que no es simpático tener a los medios en contra, cuando sabemos cómo se manejan [...] el poder político es el manejo de la prensa, porque es muy difícil que los medios oficiales no estén contestes [en consonancia] a los gobiernos de turno, algunos se la aguantan y otros no (JG, Departamento Judicial de La Plata).

En consecuencia, la prensa no aparece omnipotente sino en medio de una disputa por el control de la institución penal judicial. La idea de que "casos graves hubo siempre, pero antes los Jueces leían el diario y no les importaba" o de "que no es simpático tener a los medios en contra" permiten concluir que la prensa interviene. Sin embargo, lo que termina siendo decisivo es "quién se la aguanta y quién no".

El tercer modelo, que quizá muestre mayor reflexividad por parte de los actores judiciales, señala a los medios de comunicación como una "astucia" que manipulan los mismos actores para "neutralizar" los compromisos y las responsabilidades que tendrían que honrar como parte de su trabajo en el Poder Judicial (Sykes y Matza, 1957). En este sentido, se critica la falta de oposición al statu quo reinante y la tendencia de Jueces y 
Fiscales a aplicar medidas penales severas. De manera tal que se le da un lugar subsidiario a la prensa en relación a las rutinas judiciales.

Respecto de los medios, creo que es falso que influyan tanto, creo que es una especie de autojustificación ideológica. Influyen, pero no en los niveles que ellos mismos sostienen. Sin los medios, en lugar de $75 \%$ habría $70 \%$ de prisiones preventivas. No es un elemento decisivo, es ideológico. No son condiciones externas, sino internas: conozco jueces que son absolutamente reactivos a la prisión preventiva, que no quieren dictarla, pero son incapaces de enfrentarse a las variables que empujan dentro del sistema. Es por el habitus, no por pereza (JG, Departamento Judicial de Mar del Plata).

En este modelo, los medios de comunicación no aparecen como componentes centrales en la conformación del problema de la administración de la justicia penal. Por el contrario, esos mismos medios son utilizados para que la propia incapacidad del actor judicial, o su mayor debilidad, queden al respecto desplazados o invisibilizados.

\section{Una prensa plural}

A partir de los tres modelos propuestos es posible constatar que la ascendencia que los actores judiciales le conceden a los medios de comunicación en general es diversa. En este sentido, la importancia de sugerir dichas variantes estriba en que permite apreciary complejizar- las particularidades de la relación entre la prensa y la justicia penal. Si bien puede afirmarse que según los actores existe una influencia creciente de los medios de comunicación sobre el Poder Judicial, consideramos que dicho incremento se lo debe postular siempre que se ofrezcan evidencias al respecto. Y tal como lo señala Latour (2008), para brindar estas comprobaciones resultan imprescindibles las escalas de los mismos operadores jurídicos sobre el tema. Si descuidamos estas escalas se puede caer en desconexiones interpretativas (Lahire 2006) que nos habiliten a postular el influjo de los medios sin la necesidad de demostrarlo.

Un ejemplo significativo en el que puede observarse una clara desconexión interpretativa en la confluencia entre los medios de comunicación y los operadores jurídicos es el de la "criminología mediática", propuesta por Eugenio Zaffaroni. El público, afirma este jurista,

Reclama cada vez mayor represión por efecto de una criminología mediática que no es fácil detener, porque responde a demasiados intereses generados por ella misma, como todas las industrias de seguridad [...]. Nadie con cierta experiencia judicial puede leer muchos expedientes sin reprimir la sensación de que, fuera del círculo de autores violentos $-\mathrm{y}$ aun entre éstos- cada condenado parece más tonto y torpe que otro [...]. 
En definitiva -y, por supuesto, sin subestimar el daño que causan-, creo que en la enorme mayoría de los casos estamos prisionizando a torpes desconcertados y no a quienes eligieron en plenitud. Por el peso de la criminología mediática se llenan las cárceles con un tercio de personas sin condena, o sea, con torpes cuyo delito no ha sido probado (Zaffaroni, 2011, pp. 2-4).

Frente a la sugerencia por parte de Zaffaroni de una "criminología mediática" irresistible y anónima, cuya existencia se presupone sin demostrársela en concreto, los modelos que presentamos ofrecen una imagen bastante más heterogénea de la prensa, más allá de que su injerencia parece ir en aumento. En este aspecto, parece importante "llamar la atención sobre el determinismo mediático en el que se asienta esta propuesta [...] como modo de comprensión social de la cuestión de la seguridad" (Morales, 2014, p. 120). En definitiva, los testimonios de los actores judiciales debilitan la evidencia de una justicia penal pasiva y sojuzgada por los medios de comunicación.

\subsection{Imágenes en la prensa de la justicia penal ${ }^{1}$}

Luego de mencionar el aporte que supuso recuperar la voz de los operadores jurídicos, es necesario complementar sus representaciones con lo que la prensa expresa concretamente acerca de la justicia penal en Argentina. Por lo tanto, con el segundo movimiento intentaremos caracterizar los criterios a los que apela $-\mathrm{y}$ de los que se sirve- la prensa para referirse al desempeño de dicha administración judicial. Decidimos ceñirnos a la prensa escrita porque brinda la posibilidad de acceder a noticias que quedan registradas, $\mathrm{y}$ en este sentido permiten su mejor análisis. Otros formatos o soportes comunicacionales suelen ofrecer crónicas o informes más efímeros o fragmentados, lo que vuelve más difíciles sus tipificaciones.

En este movimiento, entonces, necesitaremos hacer primero un recorrido por la prensa para luego llegar a la justicia penal. O lo que es lo mismo, la justicia penal está ahora en la prensa, sea por lo que escriben los mismos periodistas, por lo que ellos reflejan de las afirmaciones que realizan los políticos y las víctimas, o incluso al reproducir las cartas de opinión de los lectores (Latour, 1983).

\footnotetext{
${ }^{1}$ Por cuestiones de extensión, sólo transcribiremos una crónica o nota por modelo.
} 


\section{Contra las víctimas}

Una de las imágenes que se observa en la prensa escrita es la de una justicia penal "abolicionista", término utilizado con un sesgo peyorativo. Aquí las decisiones de los actores judiciales se describen, por un lado, como indulgentes para los que han cometido un delito, y por otro, como irresponsables desde el punto de vista social por el mensaje preocupante que transmiten. Acercándose, al menos en parte, a la tesis de Durkheim (2004) sobre la existencia de un conjunto de valores y creencias compartidos por los ciudadanos "medios", en este modelo se denuncia la profanación de esos ideales considerados sagrados sin que la justicia penal lleve adelante alguna medida concreta y enérgica frente al hecho delictivo.

Un ideario "buenista" que provoca miles de muertes. En una notoria violación del principio de igualdad ante la ley, la matriz abolicionista -en vigor sólo en la Argentina- sostiene que el modelo penal es estructuralmente irracional porque propone que a un mal causado a la víctima en el ayer por el delito, se le sume un nuevo mal, la pena al victimario hoy. Esta perspectiva filosófica en la cual tanto se insiste supone una versión igualitaria de la víctima y el ofensor que pasa por alto no sólo que los sujetos de ambos males son distintos, uno inmerecido y el otro merecido, sino que, además, el mal perpetrado es causa del "mal" de la sanción, cuando en realidad es un bien en cuanto permite la reparación del victimario y la seguridad para la víctima y el resto de la sociedad [...].Con la creación del Estado, las víctimas potenciales transfieren ese derecho al poder público que a cambio se compromete a proteger la vida de los ciudadanos y a tomar a su cargo la retribución a un delito mediante su sanción. Negando ese sentido fundacional del Estado, los abolicionistas penales niegan la validez del contrato [...]. En una sociedad atravesada por la impunidad, quien delinque sabe que será eximido de la sanción por el propio sistema penal que se pone a su servicio [...]. Pero en vista de los fallos aberrantes que la sociedad observa perpleja, no se trata de "ausencia de Estado", como se ha dicho, sino de una omnipresencia sesgada a favor de la delincuencia, tal como lo prueba el nuevo Código Procesal Penal, que legitima con la letra de la ley la jurisprudencia que ordena excarcelar delincuentes. Cuando es una verdad de Perogrullo que cumplir la pena efectiva aseguraría no sólo una baja en el delito extramuros -evitando futuras víctimas-, sino la posibilidad de brindar un tratamiento eficaz en condiciones dignas (Cohen, 2014).

Una cuestión central en esta imagen tiene que ver con la manera en que la prensa ha colaborado, directa o complementariamente, para divulgar y popularizar una categoría, la de abolicionismo penal, que en determinadas coyunturas hizo viable acuerdos específicos, como fue el caso de la recolección de firmas que paralizó la reforma al Código Penal en 2015. Y se trata de acuerdos que se consolidaron por medio de la subversión de los significados que históricamente ha tenido el movimiento abolicionista al respecto. Sin profundizar en los postulados de este movimiento, lo que 
se puede afirmar es que en el centro de la preocupación del ideario abolicionista está la intención de limitar el dolor que provoca la comisión de delitos. Sin embargo, la imagen general que en la prensa circula y se refuerza sobre el citado abolicionismo penal es la de individuos, en este caso personificados por determinados actores judiciales, extremadamente indolentes respecto al sufrimiento que han padecido las víctimas de ciertos ilícitos.

Aquí, por lo tanto, la justicia penal no expresa con la vehemencia necesaria el rechazo a conductas lesivas, las cuales no sólo perjudican a las víctimas concretas de los delitos sino a la comunidad en su conjunto. Tampoco cumple con su "verdadera función que es la de mantener intacta la cohesión social, conservando a la conciencia común en toda su vitalidad" (Durkheim, 2004, p. 82). Aparece en la prensa, entonces, la amenaza de la desintegración social como un elemento que permite dimensionar la vigencia de la estrecha relación entre la penalidad y la representación de la unidad o solidaridad sociales (Melossi, 2007). O dicho de otro modo, se observa en la prensa al castigo en tanto artefacto cultural, como

Una de las múltiples instituciones que construye y respalda el mundo social, produciendo las categorías compartidas y las clasificaciones autoritarias por medio de las cuales los individuos se entienden entre sí y a sí mismos. A su modo, la política penal provee un marco cultural organizador, cuyos dictados y acciones sirven como cedazo interpretativo con el cual la gente evalúa la conducta y da sentido moral a su experiencia (Garland, 2006, p. 293).

Sin la sanción de ciertas conductas delictivas, "la ciudadanía destruye el entramado de credibilidad de la Justicia", y el Estado "reconoce el regreso de la ley de la selva y la escalada de la venganza por mano propia"2. En síntesis, lo que se muestra en esta imagen es, en primer lugar, el potencial que ofrece una justicia penal "complaciente con los delincuentes" para generar conformidad e integración entre quienes se oponen a esta última (Mead, 1997). En segundo lugar, evidencia que para lograr esa conformidad se deben evocar acusaciones que remitan a intereses de índole general, más allá de los acontecimientos particulares (Boltanski, 2000).

\section{Contra la eficacia}

Podemos especificar una segunda imagen con la que la prensa se refiere al desempeño de la justicia penal, la cual hace hincapié en su ineficiencia, en su abarrotamiento, en su 
desidia o en su lentitud. Si bien no se trata de rasgos intercambiables, lo dicho hace posible mostrar a la administración judicial como desprovista, al menos en términos generales, de los resultados y alcances que se esperan teniendo en cuenta el poder del Estado del que se trata.

Las deficiencias de la Justicia y sus consecuencias. El deterioro del funcionamiento judicial se advierte en una multiplicidad de dimensiones desalentadoras. Es ínfimo el porcentual de crímenes que resultan esclarecidos; es irracionalmente prolongada la duración de los procesos; es escaso el número de presos con condena firme y es notoria la morosidad que tienen las causas que involucran actos de corrupción. Si bien es cierto que el aumento de la conflictividad social no se resuelve únicamente en los estrados judiciales -ya que hay causas más profundas, de naturaleza económica y social, que tampoco son adecuadamente atendidas-, lo cierto es que la estructura actual de la Justicia no se halla en condiciones de brindar una respuesta razonable, debido a la acumulación de expedientes, a los métodos de trabajo, a los rigorismos formalistas y a la falta de implementación de herramientas informáticas. Esta lentitud es resultado de un largo proceso de deterioro de la calidad de una institución básica para nuestro orden sociopolítico [...]. La Justicia presenta deficiencias que afectan los derechos y la calidad institucional. Hay lentitud en los procesos, baja proporción de crímenes esclarecidos, escaso número de presos con condena firme y morosidad en causas de corrupción. Es necesario tecnificar y mejorar la organización de la Justicia y el desempeño del Consejo de la Magistratura. Debe haber mayor participación ciudadana y control público (Kirschbaum, 2008).

Una de las cuestiones más interesantes que surgen en esta imagen en torno a un aparato judicial poco eficaz es que las explicaciones que se brindan no necesariamente apuntan a la justicia penal como su máxima responsable. Incluso a veces se insinúa que como los problemas no son estrictamente judiciales es la propia justicia penal la mayor perjudicada por no poder llevar adelante una administración idónea. Estos problemas se pueden deber, por ejemplo, a la falta de una legislación adecuada, como cuando se habla de "La sensación de inseguridad es palpable, creció el número de delitos y la justicia penal está sobrepasada. Por eso el Gobierno propone cambiar de modelo de enjuiciamiento penal" (Ventura, 2007); a la ausencia de dispositivos tecnológicos apropiados, ya que "lo cierto es que la estructura actual de la Justicia no se halla en condiciones de brindar una respuesta razonable, debido a la acumulación de expedientes, a los métodos de trabajo, a los rigorismos formalistas y a la falta de implementación de herramientas informáticas" (Kirschbaum, 2008); a la carencia de una división ágil del trabajo en las investigaciones penales, cuando se afirma que "La única posibilidad de producir ese cambio es disponiendo, normativamente, la desconcentración de estas funciones dentro del proceso penal entre las partes que 
intervienen y que tienen roles claramente diferenciados, como ocurre en el modelo acusatorio" (Hauser, 2014). Por lo tanto, si bien se asume que el producto que ofrece la justicia penal no es satisfactorio, sin embargo los elementos que dan lugar a ese resultado no son patrimonio exclusivo de la justicia aludida, sino de problemas extrajudiciales.

Como otro elemento de este modelo, aparece con mayor protagonismo la voz de quienes conocen algo más en detalle la dinámica y el funcionamiento concreto de la justicia penal, sean estos periodistas, funcionarios o expertos. Como consecuencia, los diagnósticos, e incluso las críticas, que realizan están mejor documentados que en la imagen "abolicionista" que presentamos en el apartado anterior. En este sentido, los inconvenientes que se mencionan no surgen, en primer lugar, de desaciertos coyunturales sino de desarrollos de más largo plazo, lo que contribuye a que las propuestas de mejora sean de tipo "estructural". Los problemas de la justicia penal aquí no son problemas recientes, sino que por el contrario tienen un recorrido extenso que vuelve más complejo el fenómeno en cuestión.

\section{La justicia tarda, pero llega}

En muchos de los retratos periodísticos sobre el funcionamiento de la justicia penal, suele mostrársela como errática primero pero competente después. Lo anterior supone que en las diferentes instancias jerárquicas que este poder del Estado ostenta se halla la solución a la eventual falta de destreza de alguno de sus miembros. Esta imagen de una justicia penal en cierta medida autosuficiente focaliza los problemas, además de en la institución judicial como una organización concreta, en las decisiones que efectúan los propios actores.

Un año y medio preso por llamarse igual que un narco. Se llama XX, tiene 35 años, y pasó 18 meses detenido por narcotráfico. Pero la Justicia ordenó su liberación al confirmar que la detención se había realizado por error: lleva el mismo apellido que el narco buscado. Un hombre de 35 años que estuvo detenido un año y medio en la cárcel de Bouwer, en Córdoba, imputado en una causa por "narcotráfico", fue excarcelado al comprobarse que era inocente y que lo habían detenido por error porque tenía el mismo apellido que el sindicado narco al que buscaban. Fuentes judiciales dijeron que el hombre, llamado XX, fue absuelto por la Cámara 2a. del Crimen de la ciudad de Córdoba luego de que, entre otras cosas, el policía que lo arrestó no lo pudiera identificar en la rueda de reconocimiento posterior (Desconocido, 2014). 
En esta y otras crónicas similares, se enfatizan las equivocaciones de la justicia penal junto a las consecuencias nocivas que estas incorrecciones ocasionan: investigaciones mal desarrolladas, pruebas irregularmente recogidas, sentencias condenatorias desacertadas, tiempos de encierro indebidos. Sin embargo, también se puede interpretar este modelo como el que se mantiene cerca del precepto tarde $o$ temprano, la justicia siempre llega. Es por lo dicho que frente al fracaso de la justicia penal, lo que se muestra como redención es la misma justicia penal y sus diferentes instancias. Siguiendo el planteo de Ana Messuti (2008), parece introducirse la imagen de una justicia deconstruida según la cual la relación entre ésta y el derecho -en tanto regulación jurídica- es ambigua: en algunos casos inexistente -como al principio de la investigación penal-, en otras cercana -como al final-. De acuerdo con sus propias palabras,

El derecho, cuando intenta reparar lo ocurrido en el tiempo irreversible, no pretende volver atrás el tiempo, sino que reacciona ante la imposibilidad de volver atrás el tiempo. En todo caso podemos decir que la justicia [...] es el intento de reparar en la medida de lo posible esa imposibilidad: es decir, intentar que lo incancelable sea en cierta medida reparable, o se perciba como reparable, aunque en realidad no lo sea (Messuti, 2008: 243-4).

Como consecuencia, este modelo muestra por un lado las dificultades que tiene la justicia penal en la práctica para hacer del derecho algo "infalible”. Y por otro lado, que más allá de esto sí puede hacer el intento de reparar en parte el mal ocasionado, brindando la impresión de que la justicia tarda, pero llega.

\section{Haciendo justicia}

Otra imagen muy presente en la prensa escrita es la de una justicia penal que, simplemente, realiza sus tareas de manera satisfactoria, cumpliendo con la misión que le es encomendada: una justicia que logra hacer justicia. Es decir, se trata de la caracterización de una administración judicial penal que está lejos de ser objetada o avasallada por la prensa. Por el contrario, es reconocida y calificada respecto a las tareas que realiza.

El juez que liberó al presunto ladrón de Palermo explicó su decisión. El titular del Juzgado Nacional en lo Criminal de Instrucción $N^{\circ} 49$, Dr. Facundo Cubas, explicó los motivos por los cuales fue excarcelado el hombre acusado de robo en Palermo que fue "protegido" por el actor Gerardo Romano para que no lo golpearan. "En el caso no se presentan ninguno de los riesgos procesales previstos en la ley que hubieran permitido el dictado de la prisión preventiva, dado que el justiciable no 
posee antecedente condenatorio alguno, se constató que vive donde indicó y no registra ningún pedido de captura dispuesto por otro Tribunal", explicó el juez, según pudo saber LA NACION. Además, aclaró que "las características del hecho y su encuadre legal -robo en grado de tentativa, artículos 42 y 164 del Código Penal-, tampoco autorizan la prisión preventiva". En ese sentido, el magistrado explicó que "adoptar una decisión distinta hubiera significado violentar las normas que para estos hechos estipulan la Constitución Nacional, los Tratados Internacionales suscriptos por nuestro país y el mencionado Código Procesal" (Desconocido, 2014).

Es importante aclarar que la congruencia de la justicia penal a la que hace referencia esta nota no es de tipo jurídico en primer lugar, sino ligado a exigencias sobre un sentido de justicia más general ${ }^{3}$. Se trata de casos en los que las decisiones tomadas fueron diferentes, es decir, que generaron desenlaces diversos, sin embargo por medio de una actitud descriptiva la prensa las muestra como convenientes. En esta imagen no parece haber lugar para la controversia o para la disputa, entre otras cuestiones porque las crónicas no ahondan - al menos principalmente- en la justicia penal desde un punto de vista técnico, sino desde los múltiples significados que se le pueden adjudicar a decisiones que resuelven conflictos interpersonales. Tal como lo plantea Boltanski para analizar el vínculo flexible que existe entre las reglas y su aplicación, la prensa parece considerar que en ocasiones la justicia penal

Para actuar de manera más apropiada, si bien no debe observar siempre la regla al pie de la letra, al menos sí el espíritu de la regla. Así se actuaría a favor del bien común [...]. En cuanto al hecho de privilegiar el espíritu de la regla por sobre la letra de la regla, ello proporciona una potente base moral para acomodarse a las tensiones entre incertidumbre y reglas que pueblan la realidad social (Boltanski, 2012, pp. 60$61)$.

En última instancia, lo que define a la justicia penal en este modelo es el contexto social en el que adquieren significado sus resoluciones y prácticas reales que provienen de una institución destinada a favorecer el bien común (Garland, 2006, p. 225). A lo dicho, podemos sumar que se trata de una nueva evidencia que permite

\footnotetext{
${ }^{3}$ Cuando hablamos del sentido de justicia, lo hacemos a partir de aquello que las personas consideran aceptable teniendo en cuenta la situación en la que se encuentran. Así las cosas, se observa que la cuestión de la normalidad tiene un vínculo preciso con el sentido de la justicia ya que "cuando se discute la normalidad de un reclamo, lo que está en juego es la justicia, aun cuando el caso en cuestión no termine finalmente en los tribunales. Además, en un caso, quienes protestan lo hacen porque su sentido de la justicia ha sido ofendido" (Boltanski, 2000, p. 22). Tal como lo sugiere Herbert Hart, "Las características distintivas de la justicia y su conexión especial con el derecho comienzan a surgir si se observa que la mayor parte de las críticas hechas mediante el uso de las palabras "justo" e "injusto", podrían ser expresadas casi igual mediante las expresiones "equitativo" ("fair") y "no equitativo" ("unfair")" (1998, p. 197; Matza, 2014, p. 166).
} 
objetar el razonamiento que supone una justicia penal debilitada o incluso sofocada por la prensa. Antes bien, se resuelva por un encarcelamiento o por una excarcelación, las crónicas presentan a los actores judiciales como ajustados a lo que debieron hacer.

\section{Contra los vulnerables}

En los periódicos también puede observarse caracterizaciones de la justicia penal como un bastión de los poderes más tradicionales de la sociedad, fundamentalmente los vinculados a la clase social y a la problemática de género. Lo que aparece aquí es la desigualdad considerada promotora de selectividad, sea para reprimir a unos como para facilitar impunidad de otros. Es frecuente que para hacer referencia a esta justicia penal contra los más vulnerables, la prensa mencione a expertos o referentes en la materia como una forma, en algunos casos de validar la noticia, y en otros, de mantenerse imparcial a la controversia.

Ricos y pobres, derechos diferentes. "Se está produciendo, de manera sorprendente, una duplicación del derecho penal: derecho mínimo y tolerante para los ricos y potentes; derecho máximo e inflexible para los pobres y los marginados." En su conferencia de apertura del III Congreso de la Asociación Interamericana de Defensorías Públicas, el jurista Luigi Ferrajoli consideró "doloroso y doliente" lo que llamó "el acceso o mejor decir, el no acceso, a la Justicia de los sujetos débiles por razones sociales, o de género, o de edad, o de otras condiciones personales y sociales". Ferrajoli habló de la "extrema desigualdad de las personas frente a la Justicia", lo que sumado a la prolongación de los procesos "deriva, para las personas más pobres, en una denegación de justicia" [...]. También cuestionó, como factor de la "creciente desigualdad", el carácter "siempre más marcadamente clasista de la Justicia penal en todos los países occidentales: desde Italia a la Argentina y el Brasil" [...]. Por eso las cárceles están llenas de "sujetos pobres y marginados, inmigrantes, negros, toxicodependientes, detenidos por pequeños delitos contra el patrimonio". Consideró que se trata de "una prisionalización en masa de los pobres, debida a una degeneración clasista de la Justicia penal y fuertemente sostenida por una ideología de exclusión que criminaliza a los pobres, los marginales o peor aún, a los que se considera 'diferentes' -el extranjero, el islámico, el inmigrante clandestino- bajo la insignia de una antropología racista de la desigualdad" (Desconocido, 2008).

Vale mencionar que la selectividad penal que refleja la prensa en este modelo es un tema sumamente trabajado desde la criminología crítica (Lea y Young, 2008; Young, 1975;), pasando por la sociología de la penalidad (Pavarini y Melossi, 1983; Rusche y Kirchheimer, 1984) hasta los estudios sobre género (Pitch, 2009). En la actualidad la literatura especializada sugiere, por ejemplo, que lo que está mutando, aunque sea gradualmente, es el proyecto que el control formal encarna en las sociedades. El 
objetivo real ya no es gestionar la fuerza de trabajo excedente por medio de políticas sociales como sucedía anteriormente, sino regular a los excluidos por medio de dispositivos penales (De Giorgi, 2006). Es entonces cuando, según la expresión acuñada por Wacquant $(2004,2010)$, se da el paso del Estado social al Estado penal ${ }^{4}$.

Si bien con menos detalles y rigurosidad, aquello que los periódicos hacen circular en este modelo son reflexiones que surgen de espacios de pensamientos "expertos", y que logran una considerable difusión. Como dijimos al comienzo de este apartado, se advierte en la prensa escrita la presentación de asimetrías sociales que la justicia penal hace proliferar en relación a la persecución de determinado tipo de infractores. Y en este sentido, lo que se distingue en ciertos casos son los periódicos que parecen ir en la línea de la información que muestran, sirviéndose de personas reconocidas para darle mayor entidad o respaldo a la noticia, de otros casos donde se presenta una información que si bien amerita ser publicada, no despierta en el diario implicación al respecto.

\section{Fuera de los límites de la ley}

El último modelo al que haremos referencia es aquel que deja ver una justicia penal indebida, la cual puede oscilar entre la abulia y el envilecimiento. Si bien la prensa apela a diferentes calificativos, consideramos útil agruparlos en una misma imagen porque todas ellas tienen en común plantear objeciones severas a la legitimidad del ámbito judicial en sede penal. Dicho esto, es importante marcar una diferencia con la primera imagen, la de la justicia abolicionista, y es que en esta última hay una reprobación pero no se pone en duda la convicción de los actores judiciales al respecto: están desacertados pero persuadidos por sus ideales. Por el contrario, en esta imagen de los límites de la ley, se muestra a los actores judiciales más especuladores u oportunistas, dispuestos a transigir si eso les reportara algún tipo de beneficio.

Una vez más, el viejo anhelo de una Justicia adicta. [...] Un golpe de Estado contra la Justicia, para convertirla definitivamente en adicta al kirchnerismo, es un viejo sueño de la familia gobernante. Ya lo intentó con la ley de reforma judicial, el plan

\footnotetext{
${ }^{4}$ Este Estado penal se expande a partir de dos procedimientos fundamentales: uno que radica en reajustar los servicios sociales a manera de herramienta de control para los grupos más revoltosos, como por ejemplo la obligación de aceptar cualquier tipo de trabajo que le sea ofrecido a una persona, bajo pena de perder el derecho a la asistencia que recibe (workfare). El otro tiene que ver con la utilización masiva y sistemática del encierro, con el cual se intenta contener, o incluso neutralizar, en el ámbito ciudadano los inconvenientes que provoca la falta de trabajo o su precarización; respecto de esto último, Wacquant (2010) encuentra una relación decisiva entre el ensanchamiento punitivo y la desintegración del gueto.
} 
más ambicioso para tomar el control del Consejo de la Magistratura y, por lo tanto, de la designación y destitución de los jueces. Ese plan fracasó cuando la Corte Suprema de Justicia declaró inconstitucional esa ley [...]. Impotente hasta ahora para colonizar a toda la Justicia, el kirchnerismo parece haber elegido el camino de minigolpes de Estado. Desplazar a jueces y fiscales decisivos para causas importantes y conquistar el control de la Cámara de Casación, la última instancia penal antes de la Corte Suprema de Justicia [...]. El mismo día en que otro tribunal quedó integrado en la Cámara de Casación (nombrado totalmente por el kirchnerismo ), un fiscal general caía en Tucumán. Se trata de Gustavo Gómez, fiscal ante la Cámara Federal Penal de esa provincia, que tiene en su poder la causa contra Milani por la desaparición (asesinato) del soldado Alberto Ledo. El fiscal de primera instancia, Carlos Brito, había pedido la declaración indagatoria de Milani (antesala de un procesamiento) en esa investigación [...]. El poder de los fiscales está, en cambio, en impulsar las investigaciones o en dejarlas morir. Gómez cayó porque no quiso dejar morir la causa contra Milani. Cabral cayó porque había escrito un voto que cuestionaba constitucionalmente el tratado con Irán, que compromete personalmente a la Presidenta y a su canciller. Los minigolpes de Estado están en marcha (Morales, 2015).

La justicia penal es señalada aquí de tres maneras diferentes: como algo ya reprobable, como algo que se está volviendo reprobable, o como algo que intentan volver reprobable. De cualquier modo, todas estas posibilidades confluyen en la imagen de una institución degradada de alguna u otra forma, sobre la que cabe hacer una intervención contundente, sea purgándola, sea blindándola frente a las injerencias externas. Asimismo, aquí la prensa no exhibe a la justicia penal "aislada", sino amalgamada a las autoridades políticas, las que incluso resultan ser una amenaza para aquella, o porque estas autoridades la quieren adicta o porque les provoca "giros imprevistos".

Así pues, uno de los atributos de este modelo es que confirma el vínculo complejo e inestable que existe entre la justicia penal y el ámbito político, el que parece estructurarse a partir de una lógica de prebendas que fluctúan de un lado al otro. En concreto, la prensa alude a representantes y autoridades políticas que no critican al Poder Judicial en sede penal, como ocurría en el primer modelo cuando se calificaba de “saca-presos" a ciertos operadores jurídicos. Más que una "persecución política” a la justicia penal, las crónicas reflejan un uso hecho, desde la política de esa misma justicia para intereses que le son propios.

Si bien existen trabajos que ya han señalado el entramado de relaciones y criterios poco claros entre justicia penal y campo político, tanto en la selección como en los nombramientos de cargos y funciones judiciales importantes (Gutiérrez y Álvarez, 
2009; Sarrabayrouse, 2004), lo que nosotros podemos agregar al respecto es que dicho entramado redunda en algo distinto a lo que la literatura criminológica más reciente denomina "populismo punitivo" ". Esto último porque en las crónicas los políticos no atacan a los actores judiciales para obtener ventajas electorales, sino que se sirven de ellos situándolos de su lado. Y lo dicho cabe también para los propios actores judiciales, que aceptan ser promocionados pretendiendo avanzar en la escala judicial sin desconocer que ese "impulso político" no es un acto desinteresado. Por lo tanto, en esta imagen no se advierte ni la utilización demagógica por parte de la clase política del fenómeno del delito urbano, ni la supuesta indulgencia de los actores judiciales respecto de los delincuentes. Abreviando, aquí la justicia penal y el campo político no se encuentran enfrentados como exigiría el desarrollo de algún tipo de "populismo punitivo", sino que ambos se hallan tensamente mancomunados.

\section{Discusión}

\subsection{Justicia penal y prensa: entre las críticas y las justificaciones}

En los títulos anteriores describimos el doble movimiento que involucra a la justicia penal y a la prensa en Argentina: el primero, que va desde lo que publican los periódicos sobre la justicia penal a lo que perciben al respecto los actores judiciales. Teniendo en cuenta la apreciación de estos actores, la prensa puede caracterizarse como hegemónica, en el sentido que resulta decisiva para explicar el funcionamiento de la justicia penal. En segundo término, otros actores hicieron hincapié en que la prensa es un elemento importante que debe tenerse en cuenta, pero al que se le puede oponer resistencia si existe voluntad para hacerlo. El tercer modelo que presentamos es el que agrupa a los operadores jurídicos que califican a los medios de comunicación, y a la prensa en particular, como una "astucia" de la que se sirven los mencionados operadores

\footnotetext{
${ }^{5}$ El concepto "populismo punitivo" fue propuesto originalmente por Anthony Bottoms en 1995 en su artículo The philosophy and politics of punishment and sentencing. Por medio de este concepto sugirió la existencia de un uso instrumental del derecho penal por parte de los gobernantes que se asienta en la asunción de que la ciudadanía exige sanciones más severas hacia la delincuencia. A partir de allí ha tenido diferentes definiciones. Aquí nos interesa destacar, fundamentalmente, dos características que suelen atribuírsele: por un lado, la escasa relevancia que tienen en la elaboración de la política criminal los expertos tradicionales. Por el otro, el lugar preponderante que ocupa el control del delito en las contiendas electorales (Garland, 2005).
} 
para "neutralizar" sus propios deberes y obligaciones como miembros de la justicia penal.

El segundo movimiento que analizamos es el que parte de la actuación de la justicia penal y desemboca en lo que redacta la prensa sobre la cuestión. Acerca de esto último, lo que nos interesa considerar ahora es qué tipo de críticas y justificaciones se pueden extraer al respecto. Más específicamente, queremos reexaminar lo que exhibe la prensa, cuáles son los rasgos más destacados que aparecen allí sobre la justicia penal y sus integrantes, bajo qué presupuestos se lo hace, pero ahora teniendo en cuenta tales críticas y justificaciones

\section{De la crítica y la justificación}

Si miramos en conjunto las imágenes que ofrece la prensa sobre la justicia penal, lo que parece estar en tensión es aquello que al criticarla se considera que ha ofendido o traicionado, o que al ponderarla se estima que ha logrado. En este sentido, es posible señalar que los periódicos se encuentran enfrentados a una exigencia de justificación respecto a lo que informan, justificación que debe entenderse ligada de manera inseparable a la capacidad de sus lectores de llevar a cabo una operación crítica. Por lo tanto, en la prensa la justificación es necesaria tanto para propagar una crítica sobre la justicia penal, como para evitar la crítica de sus propios lectores sobre el modo de presentar la información. Vale aclarar que la exigencia de justificación a la que hacemos referencia no tiene que ver, en primer lugar, con la precisión o rigurosidad jurídica de aquello que se está publicando, incluso tampoco con su veracidad, sino con la necesidad de respaldar lo que se critica o pondera de la justicia penal en esa misma nota. Para ser más exactos, la prensa debe hacer que la información brindada no sea incoherente para sus lectores, teniendo en cuenta las situaciones sobre las que se están informando. Entendidas así las cosas,

La idea de crítica sólo cobra sentido dentro del diferencial existente entre un estado de cosas deseable y un estado de cosas real. Para dar a la crítica el lugar que se merece en el mundo social, debemos renunciar a reducir la justicia a la fuerza o a dejarnos cegar por la exigencia de justicia hasta el punto de ignorar las relaciones de fuerza existentes. Para que la crítica sea válida debe estar en condiciones de poder justificarse, es decir, de aclarar los puntos de apoyo normativos que la fundamentan, sobre todo cuando se enfrenta a las justificaciones que hacen de sus acciones quienes son objeto de la misma. La crítica no deja de hacer referencias a la justicia, ya que si la justicia no fuese más que un señuelo ¿qué sentido tendría la crítica? (Boltanski y Chiapello, 2002, p. 72) 
Tomando en cuenta estos postulados, podemos presentar un cuadro que muestre las distintas imágenes sobre la justicia penal que recuperamos de la prensa, agrupadas en torno a un conjunto de características predominantes.

\begin{tabular}{|c|c|c|c|c|c|c|}
\hline Justicia Penal & $\begin{array}{l}\text { Contra las } \\
\text { víctimas }\end{array}$ & $\begin{array}{l}\text { Contra } \\
\text { la } \\
\text { eficacia }\end{array}$ & $\begin{array}{l}\text { Tarda, } \\
\text { pero llega }\end{array}$ & $\begin{array}{c}\text { Haciendo } \\
\text { justicia }\end{array}$ & $\begin{array}{c}\text { Contra los } \\
\text { vulnerables }\end{array}$ & $\begin{array}{c}\text { Fuera de los } \\
\text { límites de la } \\
\text { ley }\end{array}$ \\
\hline $\begin{array}{c}\text { Rasgo } \\
\text { preponderante }\end{array}$ & $\begin{array}{l}\text { Indolencia, } \\
\text { insensibilidad }\end{array}$ & $\begin{array}{l}\text { Lentitud, } \\
\text { impericia }\end{array}$ & $\begin{array}{l}\text { Falibilidad, } \\
\text { rectificación }\end{array}$ & $\begin{array}{l}\text { Idoneidad, } \\
\text { competencia }\end{array}$ & $\begin{array}{c}\text { Conservadurismo, } \\
\text { clasismo }\end{array}$ & $\begin{array}{l}\text { Servilismo, } \\
\text { subordinación }\end{array}$ \\
\hline $\begin{array}{l}\text { Presupuesto o } \\
\text { aspiración }\end{array}$ & $\begin{array}{l}\text { Sociedad } \\
\text { moralmente } \\
\text { integrada }\end{array}$ & $\begin{array}{l}\text { Poder } \\
\text { Judicial } \\
\text { ágil }\end{array}$ & $\begin{array}{c}\text { Proceso con } \\
\text { un } \\
\text { desenlace } \\
\text { justo }\end{array}$ & $\begin{array}{l}\text { Proceso } \\
\text { plenamente } \\
\text { válido }\end{array}$ & $\begin{array}{l}\text { Sociedad con } \\
\text { mayor igualdad }\end{array}$ & $\begin{array}{c}\text { Poder } \\
\text { Judicial } \\
\text { competente y } \\
\text { legítimo }\end{array}$ \\
\hline $\begin{array}{c}\text { Critica o } \\
\text { justificación }\end{array}$ & Valores & Eficie & Enmienda & $\begin{array}{l}\text { Bien } \\
\text { Común }\end{array}$ & Just & Irregularidad \\
\hline $\begin{array}{l}\text { Calificación } \\
\text { del actor y/o la } \\
\text { institución }\end{array}$ & $\begin{array}{l}\text { Condescendiente, } \\
\text { irresponsable }\end{array}$ & $\begin{array}{l}\text { Obsoleta, } \\
\text { retrasada }\end{array}$ & $\begin{array}{c}\text { Inexacta, } \\
\text { providencial }\end{array}$ & $\begin{array}{c}\text { Justa, } \\
\text { adecuada }\end{array}$ & $\begin{array}{l}\text { Reaccionaria, } \\
\text { al servicio de los } \\
\text { poderosos }\end{array}$ & $\begin{array}{l}\text { Claudicante, } \\
\text { poco } \\
\text { profesional }\end{array}$ \\
\hline
\end{tabular}

De las seis figuras proporcionadas, cuatro son las que llevan adelante críticas a la justicia penal, esto es, que la califican como inapropiada, más allá de que lo hagan invocando premisas diferentes, cuando no incompatibles. Se trata de la organización judicial vista como fuente de indignación, sin la cual sería poco probable que una operación crítica pudiese emprenderse. Dicha indignación no necesariamente genera una crítica estructurada, dado que para que esto ocurra es indispensable un respaldo teórico y una elocuencia argumentativa que consigan convertir un padecimiento singular en un problema ligado al bien común ${ }^{6}$. Por el contrario, la mayoría de las veces nos encontramos en la prensa frente a críticas "ordinarias" sobre la justicia penal, en el sentido de que se relacionan con las insatisfacciones de los actores en el desarrollo de la vida cotidiana, y no con enfoques metacríticos que ofrezcan una mirada en conjunto sobre la cuestión (Boltanski, 2009). En consecuencia, las fuentes de indignación de las que se alimenta la prensa -o que ella misma engendra- para caracterizar y desaprobar a la justicia penal son en lo fundamental de cuatro tipos:

\footnotetext{
${ }^{6}$ Es por este motivo que se habla de dos niveles en la expresión de una crítica: un nivel primario situado en el ámbito de las emociones, que es imposible hacer callar y que siempre está dispuesto a inflamarse ante la presencia de la menor situación novedosa que fuerce la indignación, y un nivel secundario, reflexivo, teórico y argumentativo, que permite mantener la lucha ideológica y que constituye la fuente de conceptos y esquemas que permitirán ligar las situaciones históricas que pretenden someterse a crítica a valores susceptibles de universalización (Boltanski, 2009).
} 
- Como aquella que menoscaba a las víctimas, privilegiando al delincuente. Por estas razones, pone en riesgo la cohesión misma de la sociedad al desatender valores fundamentales para esta última.

- Como aquella que se transforma en una actividad carente de la agilidad y la destreza necesarias, ofreciendo un desempeño insuficiente de acuerdo con las exigencias requeridas.

- Como aquella que profundiza las desigualdades sociales materializando la endémica selectividad penal. Posee además un conservadurismo que rehúye a los enfoques renovadores sobre la problemática del delito.

- Como aquella que convalida los abusos del poder político debido a su falta de independencia o a su sumisión. Los actores judiciales son temerosos a raíz de los compromisos espurios que asumieron.

Una de las cuestiones que surge de observar las distintas formas de indignación es que difícilmente puedan mantenerse unidas dentro de una propuesta congruente, puesto que cada una de las imágenes que ofrece la prensa hace hincapié en determinadas características, prescindiendo de las otras. Por ejemplo, en algunos casos se destaca que la justicia penal debe contribuir a preservar ciertos valores, auspiciando una sociedad moralmente integrada, y en otros, se anhela una justicia penal que transforme algunos valores y no contribuya a ampliar las brechas generadas por la desigualdad social. Hay crónicas que reclaman una justicia penal ágil y dinámica que dé respuestas expeditivas frente a los conflictos que gestiona; y hay crónicas que reparan en la necesidad de construir o reconstruir sin premuras los canales de acceso a los cargos de la justicia para que esta última goce de mayor legitimidad y calidad en sus integrantes. Más concretamente, las demandas -y las expectativas- son distintas si las críticas se fundamentan en la indolencia, la lentitud, el conservadurismo o el servilismo. La prensa, entonces, parece transmitir, y en algunos casos encarnar, diferentes manifestaciones de reprobación sobre lo que la justicia penal es, no es, o debería ser; y es por este motivo que se vuelve más difícil afirmar que la influencia que la primera estaría ejerciendo sobre la segunda por medio de sus críticas se encamina sólo en una dirección. 
Como también hemos visto, no sólo son recriminaciones las que prodiga la prensa sobre la justicia penal: en muchas oportunidades ocurre que los periódicos destacan lo que la mencionada justicia hace correctamente -como corresponde- de acuerdo a sus exigencias, sea esto desde el comienzo del proceso penal, sea hacia el desenlace. Se trata de noticias en las que se hace circular determinadas voces por medio de las cuales se justifica y confiere sentido a la administración penal de la justicia, facilitando cierta adhesión a la necesidad de que esta última actúe como actúa. Los pilares justificativos que se observan en la prensa respecto de la justicia penal tienen que ver, genéricamente, con la consecución de objetivos que son moralmente aceptables y contribuyen a una mejor convivencia de los ciudadanos. Pueden caracterizarse de la siguiente manera:

- Una justicia penal cuya referencia central es el bien común, es decir, la equidad como un valor implícito. Esto último genera la percepción de un adecuado desempeño de la mencionada justicia.

- Una justicia penal cuya referencia central es la enmienda, en el sentido de que la inequidad cometida al comienzo es, al menos en parte, remediada con posterioridad, lo que resucita la experiencia compartida de la equidad.

Tanto para los casos que han sido irregulares al comienzo de la investigación pero concluyeron ecuánimemente así como para aquellos procesos que fueron realizados desde el inicio dentro de un marco de validez, lo que surge es una justicia penal caracterizada por una respuesta que trae aparejada cierta solución. En definitiva, la justicia penal no es aquí, en lo primordial, fuente de indignación sino una institución que contribuye al bienestar de las personas a fuerza de brindar soluciones satisfactorias en función de lo que corresponde que ofrezca.

\section{Reflexiones finales}

Una de las características más relevantes respecto al modo en que la prensa es percibida por la justicia penal en el ámbito argentino es la de la pluralidad, puesto que los actores judiciales ofrecen al menos tres criterios con los que evalúan su influencia: una prensa hegemónica, una prensa merced al voluntarismo judicial y una prensa utilizada por los mismos operadores jurídicos para auto-justificarse. Reconocer la pluralidad que surge 
de los testimonios de dichos operadores hace posible, por un lado, distinguir los matices que según sus propias escalas ofrece la cuestión de la prensa y la justicia penal. Por el otro, evitar las desconexiones interpretativas que surgen cuando se ofrecen postulados acerca de la cuestión sin demostrárselos. Y a partir de los testimonios recogidos se hace posible también relativizar la imagen de una justicia penal sometida por los medios de comunicación en general.

Cuando es la prensa la que califica a la justicia penal, la diversidad de imágenes se incrementa, ofreciendo cada una de ellas componentes, críticas y justificaciones que surgen de diferentes presupuestos. Una de estas imágenes es de la una justicia penal que se desempeña contra las víctimas, que ampara y tolera a los delincuentes sin medir las consecuencias que esto acarrea respecto a la desintegración social. Otra imagen que brinda la prensa sugiere que el funcionamiento de la justicia penal se realiza contra la eficacia como consecuencia de inconvenientes estructurales que padece esta última, generando un muy deficiente desempeño en sus tareas. La tercera figura mencionada es la que caracteriza a una justicia que tarda pero llega, de la que se desprenden dos cuestiones fundamentales: primero, los inconvenientes que en su labor cotidiana muestra la justicia penal para ser incuestionable. Y segundo, que sin bien errante, la misma justicia penal no cede en el esfuerzo por subsanar el daño que ella misma ha causado con anterioridad. También la prensa refleja en muchas ocasiones que se está haciendo justicia, más específicamente, que la justicia penal en sus resoluciones y prácticas concretas se muestra como una institución que busca beneficiar al bien común ajustándose los operadores jurídicos a lo que deben hacer. Hay casos en los cuales los periódicos resaltan la selectividad de la justicia penal, y cómo esta última actúa contra los más vulnerables reforzando las desigualdades sociales. Sin embargo, en algunas crónicas los mismos periódicos parecen coincidir con la existencia de la mencionada selectividad, y en otros presentan la información que si bien merece ser publicada no provoca adhesión el contenido de la misma. Finalmente, hay una imagen de la justicia penal que está por fuera de los límites de la ley, puesto que los actores judiciales han sido corrompidos $-\mathrm{o}$ se dejaron corromper- por el poder político, que para lograr funcionarios "adictos" provoca sumisiones y pérdida de legitimidad en el conjunto de los integrantes de la citada justicia. 
De las distintas imágenes que brinda la prensa sobre la justicia penal, lo que se observa es la contienda entre aquello que se considera que ha ofendido o traicionado cuando se la critica, o que se estima que ha logrado a la hora de ponderarla. Acerca de las críticas, éstas surgen como resultado de distintas fuentes de indignación, las cuales no es fácil que logren mantenerse acopladas dentro de una misma propuesta a raíz de que cada una de las imágenes que muestra la prensa exaltan sólo una de las características, relegando el resto. Más en concreto, por un lado se anhela una justicia penal que ayude a preservar ciertos valores favoreciendo una sociedad moralmente integrada; y por otro, se aspira a que esa misma justicia transforme valores arraigados y evite de ese modo profundizar las asimetrías sociales. También se espera que haya una justicia penal más veloz que decida ágilmente las controversias, pero además que se tome su tiempo en la elección de los integrantes para que esa misma justicia gane en respeto y legitimidad institucional. Por lo tanto, la prensa hace circular, y en algunos casos representa, diferentes críticas sobre lo que la justicia penal es, no es, o debería ser, lo que hace más arriesgado sostener la existencia un tipo de influencia de la primera sobre la segunda que se encamina en una única dirección. En el "laboratorio" de la prensa, entonces, la justicia penal parece edificarse en base a críticas y justificaciones que provocan simultáneamente un efecto de conservación y también de cuestionamiento.

Al analizar en conjunto la relación entre las percepciones de los actores judiciales sobre la prensa y las imágenes que la prensa brinda sobre la justicia penal en Argentina pudimos evitar reduccionismos sobre ambas cuestiones, cotejando ideas que de otro modo permanecerían dispersas o inconexas. Ni la justicia penal ni la prensa afirman sólo una cosa respecto de la otra, sino que hay diversos modelos y figuras que son necesarios formular para entender el complejo vínculo entre ambas.

Como línea futura de investigación, buscaremos aportar al conocimiento de cómo la justicia penal se transformó en un problema público, señalando las demandas y estrategias desplegadas por actores judiciales y extrajudiciales, entre los cuales la prensa tiene un papel privilegiado. 


\section{Referencias}

Boltanski, L. (2000). El amor y la justicia como competencias: tres ensayos de sociología de la acción. Buenos Aires: Amorrortu.

Boltanski, L. (2005). Usos débiles y fuertes del habitus. En P. Encrevé, \& R. M. Lagrave, Trabajar con Pierre Bourdieu (pp. 167-176). Bogotá: Universidad Externado.

Boltanski, L. (2009). De la critique. Précis de sociologie de l'émancipation. Paris: Gallimard.

Boltanski, L. (2012). Sociología y crítica social.Ciclo de Conferencias en la UDP. Santiago de Chile: Ediciones Universidad Diego Portales.

Boltanski, L., \& Chiapello, È. (2002). El nuevo espíritu del capitalismo. Madrid: Akal.

Chateauraynaud, F. (2005). La coacción argumentativa. Las formas de coacción en los marcos deliberativos y las potencialidades de expresión política. Revista Europea de Ciencias Sociales, 1-18.

Cohen, D. (19 de diciembre de 2014). Un ideario "buenista" que provoca miles de muertes. Diario La Nación. Recuperado de http://www.lanacion.com.ar/1753637-un-ideario-buenista-que-provoca-milesde-muertes

De Giorgi, A. (2006). El gobierno de la excedencia: postfordismo y control de la multitud. Madrid: Traficantes de sueños.

Desconocido. (12 de junio de 2008). Ricos y pobres, derechos diferentes. Diario La Página. Recuperado de https://www.pagina12.com.ar/diario/sociedad/subnotas/3-33389-2008-06$\underline{12 . h t m l}$

Desconocido. (16 de septiembre de 2014). Estuvo preso un año y medio por tener el mismo apellido que un narco. Diario Clarín. Recuperado de http://www.lanacion.com.ar/1727676-estuvo-preso-un-ano-y-medio-por-tenerel-mismo-apellido-que-un-narco\#comunidad

Desconocido. (3 de abril de 2014). El juez que liberó al presunto ladrón de Palermo explicó su decisión. Diario La Nación. Recuperado de http://www.lanacion.com.ar/1677736-el-juez-que-libero-al-presunto-ladron-depalermo-explico-su-decision

Durkheim, E. (2004). La división del trabajo social. Buenos Aires: Libertador.

Garland, D. (2005). La cultura del control: crimen y orden social en la sociedad contemporánea. Barcelona: Gedisa.

Garland, D. (2006). Castigo y sociedad moderna: un estudio de teoría social. México: Siglo XXI.

Guber, R. (2005). El salvaje metropolitano: reconstrucción del conocimiento social en el trabajo de campo, Buenos Aires: Paidós.

Gutiérrez, M., \& Álvarez, V. (2009). La construcción de la trama política del Poder Judicial, Jornadas Preparatorias del Congreso Alas.

Hart, H. (1998). El concepto de derecho. Buenos aires: Abeledo-Perrot.

Hauser, I. (12 de octubre de 2014). Una reforma en debate. Diario Página 12. Recuperado de https://www.pagina12.com.ar/diario/elpais/1-257382-2014-10$\underline{12 . h t m}$ 
Kirschbaum, R. (1 de octubre de 2008). Las deficiencias de la Justicia y sus consecuencias. Diario Clarín. Recuperado de http://edant.clarin.com/diario/2008/10/01/opinion/o-01771605.htm

Kostenwein, E. (2015a). Vida social, justicia y seguridad: relaciones desde la prisión preventiva. En O. L. Salanueva, L. E. Aguirre, I. Berisso, A. Cuenca, M. V. Branca, M. C. Espinel, ... Kostenwein, E., Allá lejos la seguridad y la justicia. Los barrios y los problemas de la seguridad y la justicia (pp. 162-191). La Plata: La Carreta.

Kostenwein, E. (2015b). Prisión preventiva: entre los medios de comunicación y las autoridades políticas. Dereito \& Práxis, 6(11), 54-79. doi: 10.12957/dep.2015.14437

Kostenwein, E. (2015c). La Prisión Preventiva en los Márgenes Judiciales. Justicia Penal, Medios de Comunicación y Autoridades Políticas. Sortuz: Oñati Journal of Emergent Socio-legal Studies, 7(1), 12-28.

Kunz A., \& Cardinaux, N. (2004). Investigar en derecho. Guía para estudiantes u tesistas. Buenos aires: Facultad de Derecho.

Lahire, B. (2006). El espíritu sociológico. Buenos Aires: Manantial.

Latour, B. (1983). Give Me a Laboratory and I will Raise the World. En K. Knorr-Cetina \& M. Mulkay (Eds.), Science Observed: Perspectives on the Social Study of Science (pp. 141-170). Londres: Sage.

Latour, B. (2008). Reensamblar lo social. Buenos Aires: Manantial.

Latour, B. (2010). The making of Law: an ethnography of the Conseil d'Etat. Cambridge: Polity Press.

Lea, J., \& Young, J. (2008). ¿Qué hacer con la ley y el orden?. Buenos Aires: Ediciones del Puerto.

Marradi, A., Archenti, N., \& Piovani, J. (2007). Metodología de las ciencias sociales. Buenos Aires: Emecé Editores.

Matza, D. (2014). Delincuencia y deriva: cómo u por qué algunos jóvenes llegan a quebarntar la ley. Buenos Aires: Siglo XXI.

Mead, G. (1997). La psicología de la justicia punitiva. Delito y Sociedad: revista de ciencias sociales, (9-10), 6-8.

Melossi, D. (2007). Estados fuertes y definidos de la conciencia colectiva (y la idea de una "responsabilidad compartida"), Delito y Sociedad: revista de ciencias sociales, (23), 11-28

Mesutti, A. (2008). La justicia deconstruida. Barcelona: Bellaterra.

Morales, J. (1 de julio de 2015). Una vez más, el viejo anhelo de una Justicia adicta. Diario La Nación. Recuperado de http://www.lanacion.com.ar/1806495-unavez-mas-el-viejo-anhelo-de-una-justicia-adicta

Morales, S. (2014). Medios de comunicación y sentimiento de inseguridad: un recorrido por sus abordajes y nuevas preguntas. Delito y Sociedad: revista de ciencias sociales, (37), 113-132.

Pavarini, M., \& Melossi, D. (1983). Cárcel y fábrica. México: Siglo XXI.

Pitch, T. (2009). La sociedad de la prevención. Buenos Aires: AD-HOC.

Rusche, G., \& Kirchheimer, O. (1984). Pena y estructura social. Bogotá: Temis.

Sarrabayrouse, M. J. (2004). La justicia penal y los universos coexistentes. En S. Tiscornia (Ed.), Burocracias y violencia (pp. 203-238). Buenos Aires: Antropofagia. 
Sautu, R. (2003). Todo es teoría: objetivos y métodos de investigación. Buenos Aires: Lumiére.

Sykes, G., \& Matza, D. (1957). Techniques of neutralization. A theory of delinquency, American Sociological Review, 22(6), 664-670.

Ventura, A. (26 de febrero de 2007). Impulsan una reforma penal para acortar los procesos. Diario La Nación. Recuperado de http://www.lanacion.com.ar/886743-impulsan-una-reforma-penal-para-acortarlos-procesos

Wacquant, L. (2004). Las cárceles de la miseria. Buenos Aires: Manantial.

Wacquant, L. (2010). Castigar a los pobres: El gobierno neoliberal de la inseguridad social. Barcelona: Gedisa.

Williams, R. (2009). Marxism and literature. Oxford; New York University of Oxford.

Young, J. (1975). Working Class Criminology. En I. Taylor, P. Walton, \& J. Young, Critical Criminology. London: Routledge.

Young, J. (2011). El pánico moral: su origen en la resistencia el ressentiment y la traducción de la fantasía en realidad. Delito y Sociedad: revista de ciencias sociales, (31), 1-2.

Young, J. (2012). El vértigo de la modernidad tardía. Buenos Aires: Didot.

Zaffaroni, E. (2011, 23 de agosto). La cuestión criminal. Página 12, 2-4.

Ezequiel Kostenwein es Abogado (UNLP), Magister en Criminología (UNL) y Doctor en Ciencias Sociales (UNLP). Docente de la Facultad de Ciencias Jurídicas y Sociales (UNLP). Becario Posdoctoral de Conicet, trabaja la prisión preventiva y la justicia penal como problemas públicos en la Provincia de Buenos Aires. Es Coordinador del Área de Sociología de la Administración de la Justicia Penal en el Instituto de Cultura Jurídica (UNLP). Participa de proyectos de investigación acerca de representaciones sociales sobre seguridad, acceso a la justicia y marginación judicial. Es autor de Por una criminología menor: ensayos, admiraciones y aserciones (Di Plácido, Buenos Aires, 2014), y La cuestión cautelar: el uso de la prisión preventiva en la Provincia de Buenos Aires (Ediar, 2015). 